\section{SM Journal of Orthopedics}

\author{
Article Information \\ Received date: Mar 22, 2016 \\ Accepted date: Mar 24, 2016 \\ Published date: Mar 24, 2016 \\ *Corresponding author
}

Hassan Boussakri, Department of Orthopedic Surgery B4, Mohammed Ben Abdullah University 30000 Fez, Kingdom of Morocco, Email: boussakri.hassan@ gmail.com

Distributed under Creative Commons CC-BY 4.0

Keywords Myxoma; Juxta-Articular; popliteal fossa; Discussion diagnosis

\section{Juxta-Articular Myxoma of the Knee Joint}

\author{
Hassan Boussakri ${ }^{1 *}$, Abdelhalim Elibrahimi ${ }^{1}$ and Abdelmajid Elmrini ${ }^{1}$ \\ ${ }^{1}$ Department of orthopaedic surgery B4, UH HASSAN II of Fez, 30000, Kingdom of Morocco
}

\section{Clinical Presentation}

It is a woman of 42 years old, without any pathological history, which has a painful mass of left knee at popliteal fossa, beginning progressively without any inflammatory clinical or biological signs. The patient doesn't report of trauma or nerve pain (electric discharge). The radiographs (Anteroposterior (AP) and lateral) without any anomalies are shown in (Figure 1). The ultrasonography (Figure 2) and MRI of the left knee is performed (Figure 3a -b).

What is your diagnosis? : According to clinical and radiological data, a number of diagnosis are discussed:

- Nerve schwannoma.

- Myxoidliposarcomas.

- Myxofibrosarcoma.

- Juxta-Articular Myxoma.

- Synovial ganglion.

Reserved diagnosis: depending on histological examination data:

- Juxta-Articular Myxoma (Figure 4).

Review

Cardiac Myxoma is a classic tumor. The other locations none cardiac, Juxta-articular are uncommon [1]. Juxta-articular Myxoma is a rare benign tumor, with peak incidence between 30 and 50 years with a female predominance [2]. Radiological assessment: ultrasonography [3] and Magnetic Resonance Imaging (MRI) of the affected knee showed acystic appearance of the lesion, sight of the importance of water content related to mucinous component and low of collagen [4]. In the literature, there is no clear description of the MRI aspect of Myxoma Juxta-Articular and intramuscular. But histologically have the same presentation. Some authors describe the characteristics of MRI to make the difference between Myxoma Juxta - Articular and intramuscular [5].

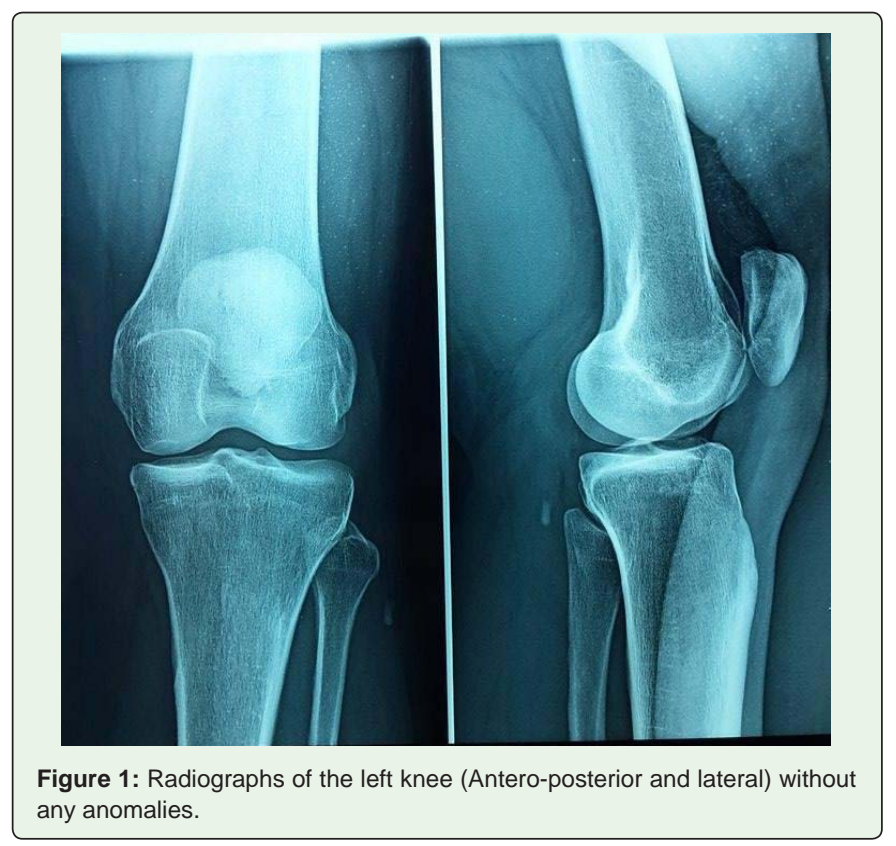



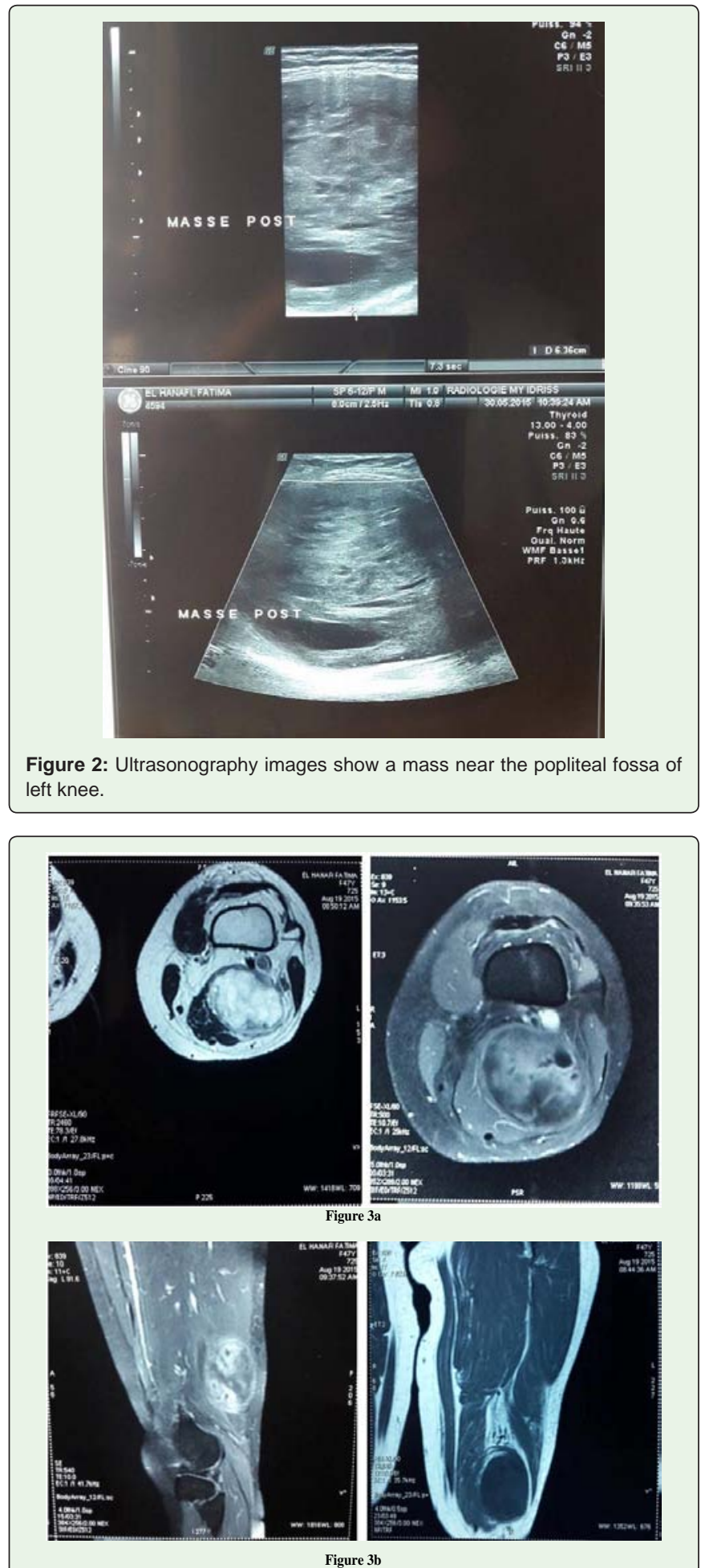

Figure 3a-b: MRI show a mass of popliteal fossa, measuring $54 \times 48 \times 67 \mathrm{~cm}$, which displaces the distal part of these membranous muscle. Hypointense in T1 and hyperintense in T2.

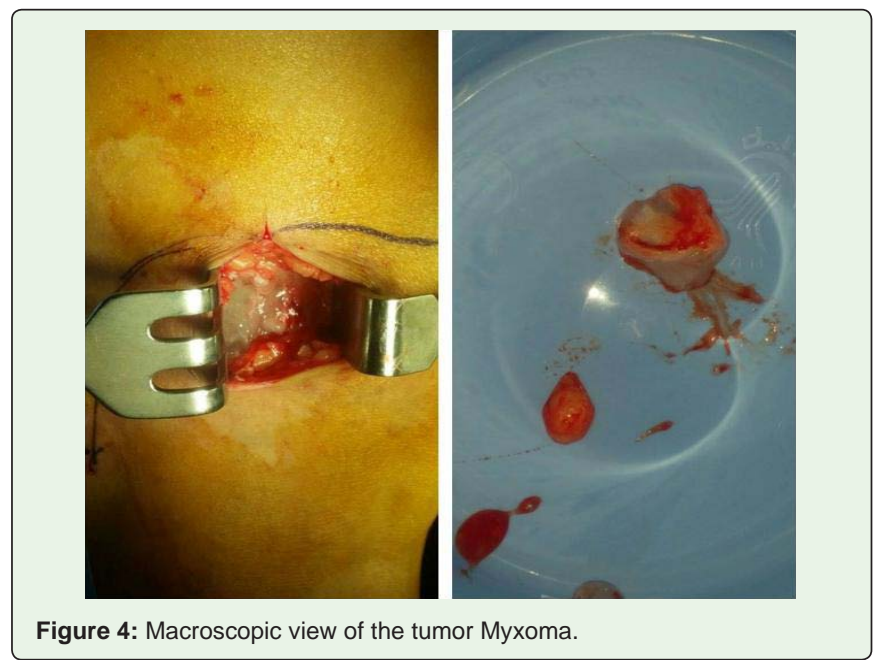

Finally, it is important to recognize this tumor, although rare, can occur. Histological examination is the only exam to confirm the diagnosis of juxta-articular Myxoma and rule out other differential diagnosis including schwannoma, liposarcomas.

\section{References}

1. Minkoff J, Stecker S, Irizarry J, Whiteman M, Woodhouse S. Juxta-articular myxoma: a rare cause of painful restricted motion of the knee. Arthroscopy. 2003; 19: E6-13.

2. Meis JM, Enzinger FM. Juxta-articular myxoma: a clinical and pathologic study of 65 cases. Hum Pathol. 1992; 23: 639-646.

3. Girish G, Jamadar DA, Landry D, Finlay K, Jacobson JA, Friedman L. Sonography of intramuscular myxomas: the bright rim and bright cap signs. J Ultrasound Med. 2006; 25: 865-869.

4. Chavent A, Gergelé F, Lambert A, Helou J, Ben Salem D. [Intramuscular myxoma of the vastus medialis. Answer to december e-quid]. J Radiol. 2011; 92: $96-98$

5. Daluiski A, Seeger LL, Doberneck SA, Finerman GA, Eckardt JJ. A case of juxta-articular myxoma of the knee. Skeletal Radiol. 1995; 24: 389-391.

6. Daluiski A, Seeger LL, Doberneck SA, Finerman GA, Eckardt JJ. A case of juxta-articular myxoma of the knee. Skeletal Radiol. 1995; 24: 389-391. 